\title{
Práticas pedagógicas em contextos educativos: intervenções ancoradas na autorregulação da aprendizagem
}

\section{Pedagogical practices in educational contexts: interventions anchored in self-regulation of learning}

\author{
Lourdes Maria Bragagnolo Frison \\ Doutoranda do Programa de Pós-Graduação em Educação - Universidade Federal de Pelotas
}

\begin{abstract}
Resumo
Apresenta-se neste artigo duas pesquisas realizadas em contextos educativos, ancoradas na autorregulação da aprendizagem, com a intenção de contribuir para a formação de professores preocupados em desenvolver competências autorregulatórias. Uma pesquisa teve ênfase na compreensão leitora, com estudantes do $8^{\circ}$ ano do Ensino Fundamental, a outra na construção dos conceitos científicos de mecânica envolvendo estudantes do curso de Licenciatura em Física. A metodologia utilizada foi intervenção pedagógica alicerçada em estratégias de autorregulação da aprendizagem. Infere-se que trabalhos dessa natureza podem desencadear mudanças nas práticas docentes, contribuindo para a promoção da aprendizagem. Palavras-chave: intervenção pedagógica, aprendizagem, leitura, ensino de física
\end{abstract}

\begin{abstract}
This article presents two researches carried out in educational contexts, anchored in the self-regulation of learning, with the intention of contributing to the formation of teachers concerned with developing self-regulatory skills. One research had an emphasis on the reading comprehension, with students from 9th grade, the other on the construction of the scientific concepts of mechanics involving students of the Licentiate in Physics course. The methodology used was pedagogical intervention based on strategies of self-regulation of learning. It is inferred that work of this nature can trigger changes in teaching practices, contributing to the promotion of learning.

Keywords: pedagogical intervention, learning, reading, physics teaching
\end{abstract}

\section{Introdução}

Com o avanço da tecnologia, no contexto atual, os estudantes acabam tendo acesso rápido a múltiplas informações e conhecimentos que são acionados quase que instantaneamente, mas tudo é lido e escrito de forma muito superficial. Distratores como whatsapp, facebook, facetime, games fazem parte da vida do aluno estando também presentes no contexto escolar, de tal forma que estudantes e os professores acabam tendo dificuldades no contexto de sala de aula. Frente a esta realidade, infere-se que a escola hoje, precisa assumir novas características, novas formas de atuação, diferentes daquelas dos séculos passados, o que gera tensionamentos, mas também exige maior investimento em oportunidades para a produção de saberes e competências mais adequadas para aprendizagem (Veiga Simão, 2006, 2013; Magalhães,
2012). Dessa forma, a sala de aula, sendo ela, local privilegiado para a implementação de práticas e estratégias para potencializar a aprendizagem dos estudantes, ainda anda a passos lentos. Essas demandas e desafios inquietam e fazem com que se invista cada vez mais em pesquisas, que possam contribuir para o desenvolvimento de práticas pedagógicas que estimulem o estudante a mobilizar estratégias autorregulatórias para aprender. Dessa forma, tanto professores, quanto estudantes precisam planejar e sistematizar suas práticas para alcançar objetivos e metas propostas (Zimmerman, 2013).

As pesquisas aqui apresentadas, resultaram de investigações realizadas com a intenção de contribuir para a condução do processo educativo de forma a estimular os estudantes para traçarem objetivos de atuação, investindo em diferentes propostas e estratégias. Tendo essa intenção, pontua-se também o papel dos professores no cenário educativo da contemporaneidade, acreditando que pesquisas como estas podem fortalecer a formação de professores, contribuindo para o exercício da docência.

Parte-se do princípio de que a autorregulação da aprendizagem é um processo pelo qual os estudantes controlam e articulam seus pensamentos, cognição, afeto, motivação e comportamento, considerados requisitos essenciais para a aprendizagem. Isso implica diretamente na forma como o professor atua (Zimmerman, 2013). Neste sentido, vários estudos nacionais e internacionais mostram a importância da realização de propostas que contribuam para que os professores ensinem os estudantes a mobilizarem estratégias para potencializem suas aprendizagens. Boruchovitch (2016, p. 402) inspirada em Cabral; Tavares (2005), Cardoso; Bzuneck (2004), Dembo (2001), afirma que entre os estudantes há falta de "consciência das suas próprias dificuldades, sobretudo das relativas a atitudes, a interesses, à motivação, ao gerenciamento de tempo, à ansiedade, à concentração, ao processamento da informação, à seleção de ideias principais, ao uso de técnicas de apoio, à autotestagem e a estratégias de preparação de exames e testes, e tendem a nem sequer preocupar-se com suas deficiências". Essa é a realidade de contextos escolares e universitários, o que desencadeia grande preocupação inquietando a todos a buscarem novas formas de atuação entre elas o 
investimento na aprendizagem autorregulada pontuada por diferentes autores Zimmerman (2013); Veiga Simão (2013), Veiga Simão; Frison (2013), Boruchovitch (2016), entre outros.

Isso posto, apresenta-se neste texto duas pesquisas realizadas em uma Universidade Federal do sul do Brasil, uma com ênfase na aprendizagem da compreensão da leitura, com estudantes do $8^{\circ}$ ano do Ensino Fundamental, outra na construção dos conceitos científicos de Mecânica por estudantes iniciantes do curso de licenciatura em Física. As duas pesquisas utilizaram a metodologia de intervenção pedagógica alicerçada na autorregulação da aprendizagem e no uso de estratégias autorregulatórias, com a intenção de maximizar a aprendizagem dos estudantes, estimulando os professores a pensarem sobre essas práticas. Ao longo do texto destacam-se estratégias de aprendizagem cognitivas, metacognitivas e motivacionais utilizadas na pesquisa (Zimmerman, 2013; Veiga Simão, 2013).

\section{Estratégias para a compreensão da leitura por estudantes do $8^{\circ}$ ano do Ensino Fundamental}

O primeiro estudo desenvolvido por Vieira, orientado por Frison (2014), teve ênfase no desenvolvimento da capacidade de compreensão da leitura de estudantes do $8^{\circ}$ ano. De acordo com as orientações dos Parâmetros Curriculares Nacionais de Língua Portuguesa (1998), para que o aluno seja um leitor competente, precisa compreender o que lê, estabelecendo relações com o que está lendo ou o que já leu. Essa concepção de leitura, traz implícita a crença e que autor e leitor estão em processo interativo. Para desenvolver a competência leitora o estudante precisa mobilizar um conjunto de habilidades como: selecionar estratégias que lhe permita compreender a leitura adequando-a a diferentes tipos e gêneros textuais; identificar a macroestrutura e a microestrutura do texto; estabelecer uma rede de relações entre enunciados; organizar e selecionar informações que compõem as diferentes partes do material; realizar inferências; localizar informações relevantes; avaliar a informação recebida e utilizar adequadamente a informação (Solé, 1998). Entende-se que esses procedimentos permitem ao estudante alcançar seu objetivo e a avançar na compreensão de diferentes leituras, as quais exigem componentes metacognitivos sobre a sua própria compreensão.

A metodologia utilizada na pesquisa foi a intervenção pedagógica, caracterizada como uma práticas de ensino planejada, implementada e avaliada com o propósito de potencializar as aprendizagens dos estudantes que delas participam (Damiani, 2012). A amostra foi constituída por 27 estudantes, 14 do gênero masculino e 13 do feminino, com idade entre 13 e 16 anos, que cursavam a $8^{\circ}$ ano do ensino fundamental, de uma instituição pública do Rio Grande do Sul. A intervenção em contexto de sala de aula foi inspirada em Veiga Simão (2006) e adaptada para o contexto brasileiro. Foram realizadas 12 sessões-aula, com enfoque nas estratégias autorregulatórias para a compreensão leitora, com duração de dois períodos semanais.
No primeiro e no último encontro, os estudantes realizaram a leitura de um texto e responderam questões de compreensão da leitura. Durante a intervenção pedagógica, foram trabalhados três textos. Para cada texto, desenvolveram-se estratégias de antecipação, planejamento, monitorização e avaliação da leitura, enfatizando a relevância da autoavaliação do desempenho realizada com a orientação da professora-pesquisadora. Foram utilizados guias de interrogação metacognitiva para que o aluno tomasse as decisões sobre a escolha das estratégias de compreensão leitora, de acordo com o momento da leitura e com a especificidade dos textos. Por exemplo: guia de interrogação utilizados antes da leitura: "O que eu sei sobre o assunto? Por que será que a professor pediu para eu ler este texto? Será que vou conseguir compreender o texto? Por quê?". Durante a leitura: "Depois de eu ler o primeiro parágrafo, confirmo minhas primeiras ideias ou hipóteses sobre o texto? Consigo explicar com minhas palavras o que acabei de ler? Penso no que poderá acontecer a seguir?". Após a leitura do texto: “Quais são as ideias principais do texto? Vou sublinhá-las e escrevê-las com as minhas palavras? Se tiver dificuldades em compreender, o que posso fazer? O que aprendi com o texto? O que preciso fazer para lembrar o que li? Que perguntas devo fazer (a mim) para me ajudar a compreender o texto?" (Vieira, 2015; Frison, 2016).

Posteriormente também foram utilizados cartões-registro, os quais objetivaram realizar feedback. As questões contidas no cartão: "Durante esta aula aprendi que [...]; Percebi que [...]; Gostaria de saber mais sobre [...]". O registro escrito possibilitou a autoavaliação da aprendizagem pelos estudantes sobre a leitura realizada. Os estudantes refletiam sobre $o$ processo e avaliavam o que tinham feito, anotando no cartão-registro os resultados obtidos, a fim de poderem reorganizar seu planejamento. O feedback sobre as etapas desse processo foi dado pela professora-pesquisadora. Investiu-se no emprego de estratégias para ler o texto e sobre as que podem ser utilizadas antes, durante e após a leitura (Vieira 2015; Frison, 2016).

Este estudo mostra a necessidade do professor sistematizar em sala de aula atividades que estimule os processos autorregualtórios dos estudantes, o que exige a regulação do ensino e o constante cuidado de realizar feedback das atividades realizadas.

Pontua-se que este estudo promoveu o envolvimento dos estudantes e indicou também que cresceu o número de estudantes que passaram a utilizar estratégias que visaram antecipar a leitura. Os estudantes, ao empregarem estratégias de antecipação da leitura, ao traçarem um plano estratégico, planejarem ações que promova a compreensão da leitura, conseguem mais facilidade organizar, elaborar e recuperar a informação. Infere-se que os estudantes ao utilizarem diferentes estratégias monitoraram melhor o modo como eles se comportam diante do texto e como controlam a consecução de seus objetivos. 


\section{Estratégias para a construção dos conceitos científicos em física por universitários}

O segundo estudo desenvolvido por Bilhalba, orientado por Frison (2015), teve ênfase na construção dos conceitos científicos em Física e foi realizado em uma universidade do sul do Brasil. A metodologia utilizada também foi uma intervenção pedagógica, planejada, implementada e avaliada com o propósito de mapear o processo autorregulatório realizado pelos participantes (Damiani, 2012). O estudo foi realizado em uma disciplina com 36 estudantes: 27 calouros e 9 veteranos. Do total, 20 concluíram a disciplina.

Notadamente os estudantes de cursos de licenciatura em Física apresentam alto índice de reprovação e evasão e ao cursarem as disciplinas, geralmente vivenciam de forma muito penosa a aprendizagem dos conceitos científicos da Mecânica que são apresentados nas disciplinas introdutórias dos cursos de Física, o que gera desmotivação e abando do curso, muitas vezes acompanhados de um sentimento de baixa autoeficácia (Bilhalba; Ayala, 2012). Esse sentimento de incapacidade está diretamente ligado a autorregulação da emoção, que pode gerar emoções negativas em relação ao ser capaz ou não de aprender.

Ao realizar esta pesquisa buscou-se propor alternativas para os estudantes pensarem e investirem em estratégia que promovessem a aprendizagem de Física. Para isso, investiu-se em estratégias autorregulatórias para trabalhar conceitos científicos referentes aos conteúdos de Física. A metodologia utilizada foi uma intervenção pedagógica, realizada com 36 estudantes da disciplina de Física Geral I, disciplina do primeiro semestre do curso. No primeiro encontro foi realizado um pré-teste, para compreender o que os estudantes sabiam sobre os conceitos científicos de velocidade e composição de movimentos, já trabalhados em outra disciplina. Dentre as estratégias trabalhadas, investiu-se na resolução de problemas utilizando as seguintes etapas: 1) destacar os conceitos presentes no enunciado do problema; 2) identificar o problema proposto; 3 ) propor hipóteses para a resolução do problema; 4) buscar expressões numéricas para testar as hipóteses; 5) testar as hipóteses; 6) encontrar o resultado. Os estudantes envolviam-se na resolução dos problemas respeitando as etapas elencadas, tendo como critério inicial entender o enunciado da questão. Dessa forma, investia-se na leitura compreensiva.

Depois da intervenção, os estudantes foram chamados individualmente para uma entrevista e nela explicavam como resolveram as questões propostas. As fases cíclicas da autorregulação da aprendizagem planejamento, execução e avaliação, foram fundamentais para o enfrentamentos dos problemas propostos (Zimmerman, 2013). A organização, a gestão do tempo, a reflexão sobre os processos de aprendizagem, o papel do aluno, o estabelecimento de objetivos (de curto e longo prazo) contribuíram para o estudante tomar consciência sobre o que tinham feito e o que deveriam modificar (op.cit.)

Como impacto os estudante demonstraram operar melhor com os conceitos de Física, indicando que essa metodologia inscrita em um processo amplo de tomada de consciência contribuiu para a aprendizagem de construção conceitual. Os resultados desse trabalho mostram o quanto novas práticas pedagógicas promovem o uso consciente dos conceitos, realçando que estas não podem ser desenvolvidos de forma imediata, exige um processo de internalização por parte do estudante e monitorização por parte do professor.

Com a realização dessa investigação percebeu-se que o ensino de Física, como outros tantos, não podem ser vistos como mera transmissão de conhecimentos. É preciso ter uma sistemática que contribua para a superação dos obstáculos, promovendo a aprendizagem dos conceitos estudados por parte dos estudantes (Bilhalba, 2015; Frison, 2016). Um ponto altamente positivo, no final do semestre não houve nenhuma reprovação dos 20 estudantes que cursaram a disciplina até o final.

\section{Conclusões}

Os estudos mostram que, quando o docente desempenha um papel mais ativo e autorregulado na promoção da aprendizagem dos estudantes, essa atitude possibilita aos alunos uma visão e atuação mais pró-ativa no processo de aprendizagem. A monitoração realizada pelo professor no decorrer das propostas de trabalho contribui para a aprendizagem do estudante, oportunizando ao professor avaliar e acompanhar a aprendizagem do aluno. A atuação regulada contribui para a organização da aula, o fortalecimento das relações, as parcerias, a ajuda colaborativa, a troca de ideais, de forma que o estudante autorregule seu aprender. É preciso prever meios, para mobilizar estratégias autorregulatórias, para potencializar aprendizagens e superar obstáculos.

As duas pesquisas mobilizaram estratégias para os estudantes avançarem em suas aprendizagens nas próprias disciplina. $\mathrm{O}$ trabalho realizado mostrou que os estudantes resolveram os problemas apresentados por meio das fases cíclicas - planejamento, execução e auto-avaliação. O estudo feito no curso de Física mostrou a importância da compreensão leitora para a resolução de problemas.

Como ponto relevante dos resultados dessa pesquisa destaca-se o monitoramento, o acompanhamento do professor, as estratégias utilizadas, com as quais o estudante sistematiza processos e atitudes com as quais desencadeia a aprendizagem. Notadamente, nestes estudos o que se torna, de algum forma imprescindível, é o feedback do professor. O professor precisa dar retorno contínuos aos estudantes sobre as atividades realizadas, para que eles possam rever o que ainda não aprenderam.

Ensinar estratégias de aprendizagem é necessário em todas as áreas e níveis, principalmente aquelas que fortalecem parcerias e trabalho colaborativo. Os estudantes quando se ajudavam mutuamente, tornam-se mais autônomos, críticos e estratégicos.

Com efeito, os dados obtidos, reforçam a ideia de que os professores precisam em sala de aula estimular os estudantes a mobilizarem estratégias adequadas à exigência da tarefa solicitada. Acredita-se que, os professores, ao investirem no uso de estratégias, contribuem para que os estudantes se tornem mais 
proficientes no domínio dos conteúdos a serem apreendidos.

\section{Referências}

Bilhalba, L. P. (2015). O desenvolvimento dos conceitos científicos de mecânica por alunos do curso de licenciatura em física: uma intervenção pedagógica alicerçada na teoria histórico-cultural da atividade e nas estratégias da autorregulação da aprendizagem. Dissertação (Mestrado em Educação). Faculdade de Educação, Universidade Federal de Pelotas/BR.

Bilhalb, L. P.; Ayala Filho, A. L. (2012). Uma análise do entendimento dos conceitos de cinemática galileana por alunos da disciplina física geral I no referencial da teoria sócio-histórica de Vygotsky. In: Congresso De Iniciação Científica, $21^{\circ}$. Anais do CIC. Pelotas.

Brasil, (1998). Parâmetros Curriculares Nacionais: terceiro e quarto ciclos do ensino fundamental: língua portuguesa. Secretaria de Educação Fundamental. Brasília: MEC/SEF.

Cabral, A.; Tavares, J. (2015). Leitura/Compreensão, Escrita e Sucesso Acadêmico: um Estudo de Diagnóstico em Quatro Universidades Portuguesas. Psicologia Escolar e Educacional, 9 (2), p. 203-213.

Cardoso, L.R.; Bzuneck, J.A. (2004). Motivação no ensino superior: metas de realização e estratégias de aprendizagem. Psicologia Escolar e Educacional, 8 (2), p. 145-155,

Damiani, M. F. (2012). Sobre Pesquisas do tipo intervenção (Painel: As pesquisas do tipo intervenção e sua importância para a produção de teoria educacional). In: Anais do XVI Encontro Nacional de Didática e Prática de Ensino. Campinas: Unicamp, p. 2882-2890.

Dembo, M.H. (2001). Learning to teach is not enough future teachers also need to learn to learn. Teacher Education Quaterly, 28 (4), p. 23-35.

Frison, L.M.B. (2016). Autorregulação da aprendizagem: abordagens e desafios para as práticas de ensino em contextos educativos. Revista Educação PUC Campinas. Campinas, São Paulo. v.21, p. 1-18.

Ganda, D. R.; Boruchovitch, E. (2016). Atribuições de Causalidade e Estratégias Autoprejudiciais. Psico-USF, Bragança Paulista, v. 21, n. 2, p. 331-340, mai./ago, p. 331-340.

Solé, I. (1998). Estratégias de leitura. Trad. Cláudia Schilling $-6^{\circ}$ Ed. Porto Alegre: Artmed.

Vieira, D. C. (2014). Estratégias de compreensão leitora ancoradas no construto da Aprendizagem Autorregulada: uma intervenção pedagógica. Dissertação (Mestrado em Educação) - Faculdade de Educação, Universidade Federal de Pelotas, Pelotas.

Veiga Simão, A. M. (2006). Auto-regulação da aprendizagem: um desafio para a formação de professores. In Bizarrro, R.; Braga, F. (Org.). Formação de Professores de Línguas Estrangeiras: Reflexões, Estudos e Experiências. Porto: Porto Ed., p. 192-206.

Veiga Simão, A.M. (2013). Ensinar para a aprendizagem escolar. In. Veiga, F.H. (Org.). Psicologia da Educação: teoria, investigação e aplicação.
Envolvimento dos alunos na escola. Lisboa: Climepsi Editores, p. 495-541.

Veiga Simão, A. M.; Frison, L. M. B. (2013). Autorregulação da aprendizagem: abordagens teóricas e desafios para as práticas em contextos educativos. Cadernos de Educação FaE/PPGE/UFPel, n. 45, p. 02-20, jul./ago.

Zimmerman, B. J. (2013).From cognitive modeling to self-regulation: a social cognitive career path. Educational Psychologist, New York, v.48, n.3, p.135-147. 